\title{
Protective Effect of Kombucha on Diabetic Nephropathy in Streptozotocin - Induced Diabetic Rats
}

\author{
Flora Olinda Dias ${ }^{1}$, Chandrakala Shenoy $\mathbf{K}^{2}$ \\ ${ }^{1,2}$ Department of Biosciences, Mangalore University, Mangalagangotri, Karnataka.574199, India
}

\begin{abstract}
Kombucha is a fermented black tea, claimed to have wide range of beneficial effects on human health functions. The present study was aimed to investigate the effect of kombucha on diabetes induced alterations in the kidney. The effect of kombucha on blood glucose, plasma protein, albumin, urea and creatinine was examined in the control and experimental groups along with histopathological studies. The results of biochemical analysis showed a remarkable improvement in metabolic profile after kombucha administration. The histological studies showed glomerular and tubular damage in diabetic control rats. The kombucha treated group showed restoration in renal architecture. Thus kombucha may be of supportive treatment to combat diabetes complications, diabetic nephropathy.
\end{abstract}

Keywords: Diabetes, Kombucha, Diabetic Nephropathy, Streptozotocin

\section{Introduction}

Diabetes mellitus (DM) is a metabolic disease associated with secondary complications such as cardiovascular and renal disease. Among the complications, nephropathy seems to be highly prevalent (Selby et al., 1990). Diabetic nephropathy refers to a spectrum of renal diseases from microalbuminuria to the progressive decline in glomerular filtration rate which may lead to end-stage renal failure (Ritz et al., 2011). At present, diabetic kidney disease affects about $15 \%-25 \%$ of diabetes patients (Hovind et al., 2003). Reactive oxygen species play an important role in high glucose-induced renal injury (Ha and Lee, 2000).

Kombucha is a sour beverage prepared from the fermentation of sugared black tea with a symbiotic culture of acetic acid bacteria and yeasts such as Acetobacter xylinum, A. xylinoides, Bacterium xylinum, Bacterium xylinoides and the novel species, Acetobacter nitrogenifigens sp. nov. and Gluconacetobacter kombuchae sp. nov., Saccharomyces ludwigii, Saccharomyces apiculatus varieties, Schizosaccaromyces pombe, Saccharomyces cerevisiae, Zygosaccharomyces bailii and Pichia fermantans (Jayabalan et al., 2014). During the fermentation process, bacteria and yeasts metabolize sucrose into a number of organic acids such as acetic acid, glucuronic acid, amino acids, antibiotics and a variety of micronutrients (Chu and Chen, 2006). Kombucha is rich in antioxidants and probiotic acids that can detoxify disease-causing toxins and hence alleviates a wide spectrum of pathological conditions. Therefore, the present study was aimed to determine the protective effect of kombucha on diabetic nephropathy in streptozotocin (STZ) induced DM.

\section{Materials and Methods}

Chemicals

STZ was purchased from Sigma Chemical Company (St Louis, MO, USA). All the other chemicals used were of analytical grade and were purchased from commercial sources.

\section{Preparation of Kombucha}

The tea decoction was prepared by adding $10 \%$ of sucrose to tap water and $0.75 \%$ of black tea leaves, boiled for 3 minutes and then cooled to room temperature. The tea decoction was filtered and poured into clean glass bottles and kombucha pellicle from previous culture was added to it. Under aerobic condition, the sugared tea was allowed to ferment for 7 days at room temperature. The kombucha obtained was filtered, sterilized and refrigerated.

\section{Experimental Animals}

The experiments were carried out in healthy adult Wistar strain Albino rats of either sex, weighing between 200-240g obtained from the Animal House, Department of Biosciences, Mangalore University, Mangalore. They were maintained under standard laboratory conditions of temperature and humidity, 12 hour light dark cycle. A standard pellet diet and water were supplied ad libitum. The experiments were conducted according to the guidelines of the Committee for the Purpose of Control and Supervision of Experiments on Animals (CPCSEA), New Delhi, India, after the approval of the research proposal by the Animal Ethical Committee of Mangalore University (CPCSEARegistration No. 232).

\section{Induction of Diabetes}

Diabetes was induced in overnight fasted rats by a single intraperitoneal injection of freshly prepared Streptozotocin (50mg/kg body weight) in $0.1 \mathrm{M}$ chilled citrate buffer ( $\mathrm{pH}$ 4.5) (Parthasarathy et al., 2007). 72 hours after diabetes induction, fasting blood glucose was determined and the rats with blood glucose above $250 \mathrm{mg} / \mathrm{dl}$ were used for the study. Rats were maintained in the diabetic state for 14 days and the treatment was started on the $15^{\text {th }}$ day after STZ- injection and this was considered as the $1^{\text {st }}$ day of treatment. The treatment was continued for 14 days. 


\section{International Journal of Science and Research (IJSR) \\ ISSN (Online): 2319-7064 \\ Index Copernicus Value (2013): 6.14 | Impact Factor (2014): 5.611}

\section{Experimental Protocol}

The rats were divided into four groups with six rats in each group.

Group I: Normal control rats

Group II: Diabetic control Rats

Group III: Diabetic rats treated with Kombucha.

Group IV: Diabetic rats treated with Glibenclamide

Kombucha $(1.71 \mathrm{ml} / \mathrm{kg})$ and Glibenclamide $(5 \mathrm{mg} / \mathrm{kg})$ was given once daily using an oral gavage for 14days.At the end of the 2 weeks of treatment period, the overnight fasted rats were anaesthetized using ketamine $22-24 \mathrm{mg} / \mathrm{kg}$ i.m., and blood was collected by heart puncture. The organs were excised after sacrifice for histological studies.

\section{Biochemical Analysis}

The body weight in experimental animals was determined by a digital balance. The fasting blood glucose concentration was determined by means of one touch ultra glucometer. Total protein, albumin, were analyzed using commercial kits (Agappe Diagnostics Ltd., Kerala). Biuret method was employed for the determination of protein (Gornall et al., 1949). Albumin was estimated spectrophotometrically by reaction with the dye bromocresol green (Doumas et al., 1977). Urea, creatinine and uric acid were assayed in blood plasma using standard kits supplied from Agappe Diagnostics Ltd., Kerala, India.

\section{Histological Study}

Renal tissues were collected, washed in ice cold saline, fixed in $10 \%$ formalin solution and embedded in paraffin. Sections were obtained by a microtome and stained with hematoxylin and eosin. The sections were then examined under a light microscope.

\section{Result and Discussion}

DM causes serious injury to the kidney tissue that leads to renal dysfunction (Eid et al., 2013). STZ-induced diabetic rats result in development of nephropathy similar to the early stage of human diabetic nephropathy (Rasch and Mogensen, 1980). STZ-induced diabetes is characterized by severe loss in body weight which was observed in the present study. The decrease in body weight observed in diabetic rats might be the result of protein wasting due to unavailability of carbohydrate as an energy source (Musabayane et al., 2005). Kombucha administration controlled this loss in body weight and also reduced symptomatic conditions such as polydipsia and polyuria along with diarrhoea.

Kidney enlargement is an early feature in both experimental and human diabetes due to an increase in the capillary length and diameter and was correlated with the degree of glycaemic control (Jefferson et al., 1983). Administration of kombucha reduced and prevented diabetes induced kidney enlargement. Oral administration of kombucha to the diabetic rats showed a marked hypoglycaemic effect by restoring the blood glucose levels to near normal. The hypoglycemic action may be due insulinomimictic action or by stimulation of glucose uptake by peripheral tissues (Burcelain et al., 1995).

The decrease in protein and albumin may be due to microproteinuria and albuminuria, and/or may be due to increased protein catabolism, which are important clinical markers of diabetic nephropathy (Mauer, 1981). The treatment of diabetic rats with kombucha caused a noticeable elevation in the plasma total protein and albumin levels as compared with their normal levels. Urea, uric acid and creatinine concentrations are also considered as a significant marker of renal dysfunction (Almdal and Vilstrup, 1988). Protein glycation in diabetes may lead to muscle wasting and increased release of purine, the main source of uric acid, as well as increased activity of xanthine oxidase and lipid peroxidation. Kombucha reversed these parameters to near normal which could be due to decreased metabolic disturbances of other pathway such as protein and nucleic acid metabolism and improved glycaemic control. This may also be due to the presence of acetic acid and glucuronic acid which helps in detoxification and removal of waste products from the blood.

Histopathology of kidney of diabetic rats showed marked degeneration of the Bowman's capsule, tubular damage, haemorrhage in the Bowman's space due to glomerular damage and dilatation of renal tubules. However, the administration of kombucha to diabetic rats exhibited an improvement in these pathological changes in the kidney. This suggests that kombucha may restore antioxidant activity and thereby reduces renal damage .The nephroprotective effect may be also be attributed to the synergistic action of the bioactive compounds such as flavanoids present in kombucha.

Table 1: Effect of kombucha on body weight, kidney weight and fasting blood glucose in control and experimental rats.

\begin{tabular}{|l|c|c|c|c|}
\hline \multirow{2}{*}{\begin{tabular}{c} 
Proup $(\mathrm{n}=6)$ \\
\cline { 2 - 3 }
\end{tabular}} & \multicolumn{2}{|c|}{ Body Weight (g) } & Kidney Weight (g) & $\begin{array}{l}\text { Fasting } \\
\text { Glucose }(\mathrm{mg} / \mathrm{dl})\end{array}$ \\
\hline Normal Control rats & $204.6 \pm 2.19$ & $232.9 \pm 3.66$ & $1.04 \pm 0.10$ & $81.32 \pm 3.63$ \\
\hline Diabetic Control rats & $209.76 \pm 2.38$ & $148.5 \pm 4.42^{* * *}$ & $1.61 \pm 0.18^{* * *}$ & $324 \pm 6.66^{* * *}$ \\
\hline Diabetic + Kombucha treated rats & $206.75 \pm 2.99$ & $198.1 \pm 2.69^{* * *}$ & $0.95 \pm 0.11^{* * *}$ & $114 \pm 5.76^{* * *}$ \\
\hline Diabetic + Glibenclamide treated rats & $207.6 \pm 2.43$ & $201.8 \pm 2.38^{* * *}$ & $0.9 \pm 0.13^{* * *}$ & $109 \pm 6.06^{* * *}$ \\
\hline
\end{tabular}

Values are given as Mean \pm SD. Values are statistically significant at $* \mathrm{P}<0.05, * * \mathrm{P}<0.01$, $* * * \mathrm{P}<0.001$; Diabetic versus normal $(\mathrm{P}<0.001)$, Diabetic versus KT treated $(\mathrm{P}<0.001)$

Diabetic versus Glibenclamide treated $(\mathrm{P}<0.001)$ 


\section{International Journal of Science and Research (IJSR) \\ ISSN (Online): 2319-7064 \\ Index Copernicus Value (2013): 6.14 | Impact Factor (2014): 5.611}

Table 2: Effect of kombucha on urea, creatinine and uric acid in control and experimental rats

\begin{tabular}{|c|c|c|c|}
\hline Groups $(\mathrm{n}=6)$ & Urea $(\mathrm{mg} / \mathrm{dl})$ & $\begin{array}{c}\text { Creatinine } \\
(\mathrm{mg} / \mathrm{dl})\end{array}$ & $\begin{array}{c}\text { Uric Acid } \\
(\mathrm{mg} / \mathrm{dl})\end{array}$ \\
\hline Normal Control rats & $31 \pm 3.74$ & $0.4 \pm 0.23$ & $0.97 \pm 0.1$ \\
\hline Diabetic Control rats & $52.03 \pm 2.94^{* * *}$ & $1.03 \pm 0.33^{* * *}$ & $2.6 \pm 0.35^{* * *}$ \\
\hline Diabetic + Kombucha treated rats & $39.7 \pm 4.19^{* * *}$ & $0.5 \pm 0.2^{*}$ & $1.2 \pm 0.38^{* * *}$ \\
\hline Diabetic + Glibenclamide treated rats & $42.5 \pm 2.37^{* * *}$ & $0.5 \pm 0.2^{*}$ & $0.91 \pm 0.06^{* * *}$ \\
\hline
\end{tabular}

Values are given as Mean $\pm \mathrm{SD}$. Values are statistically significant at $* \mathrm{P}<0.05,{ }^{*} * \mathrm{P}<0.01$, $* * * \mathrm{P}<0.001$; Diabetic versus normal $(\mathrm{P}<0.001)$, Diabetic versus KT treated $(\mathrm{P}<0.05)(\mathrm{P}<0.001)$, Diabetic versus Glibenclamide treated $(\mathrm{P}<0.05)(\mathrm{P}<0.001)$

Table 3: Effect of kombucha on protein, albumin and globulin in control and experimental rats

\begin{tabular}{|c|c|c|c|c|}
\hline Group $(\mathrm{n}=6)$ & Protein $(\mathrm{g} / \mathrm{dl})$ & Albumin $(\mathrm{g} / \mathrm{dl})$ & Globulin $(\mathrm{g} / \mathrm{dl})$ & \multirow{2}{*}{$\begin{array}{c}\mathrm{A} / \mathrm{G} \\
1.53 \pm 0.54\end{array}$} \\
\hline Normal Control rats & $6.53 \pm 0.95$ & $3.76 \pm 0.27$ & $2.77 \pm 1.12$ & $0.8 \pm 0.30^{*}$ \\
\hline Diabetic Control rats & $4.12 \pm 0.42^{* * *}$ & $1.75 \pm 0.29^{* * *}$ & $2.37 \pm 0.63^{* * *}$ & $0.87 \pm 0.35^{\mathrm{NS}}$ \\
\hline Diabetic + Kombucha treated rats & $5.5 \pm 0.58^{* *}$ & $2.46 \pm 0.34^{* *}$ & $3.04 \pm 0.72^{* *}$ & $0.87 .05 \pm .06^{\mathrm{NS}}$ \\
\hline Diabetic + Glibenclamide treated rats & $6.1 \pm 0.28^{* * *}$ & $3.13 \pm 0.09^{* * *}$ & $2.97 \pm 0.22^{* * *}$ & $1.05 \pm$ \\
\hline
\end{tabular}

Values are given as Mean \pm SD. Values are statistically significant at $* \mathrm{P}<0.05, * * \mathrm{P}<0.01, * * * \mathrm{P}<0.001$, NS: Non Significant; Diabetic versus normal $(\mathrm{P}<0.001)$, $(\mathrm{P}<0.05)$, Diabetic versus KT treated $(\mathrm{P}<0.01)$, NS, Diabetic versus Glibenclamide treated $(\mathrm{P}<0.001)$, NS

\section{Histopathological Studies}

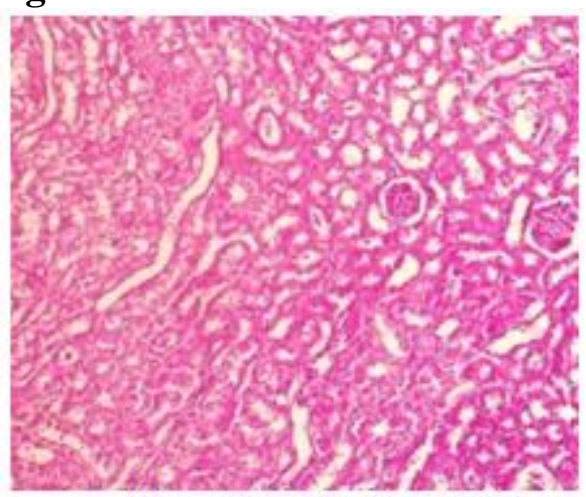

Figure (a): Normal control

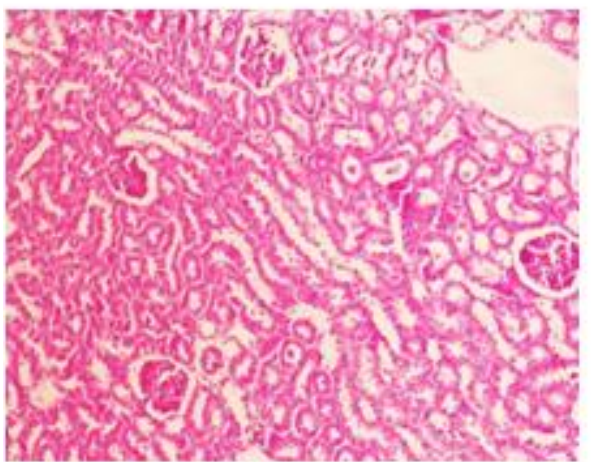

Figure (c): Kombucha treated

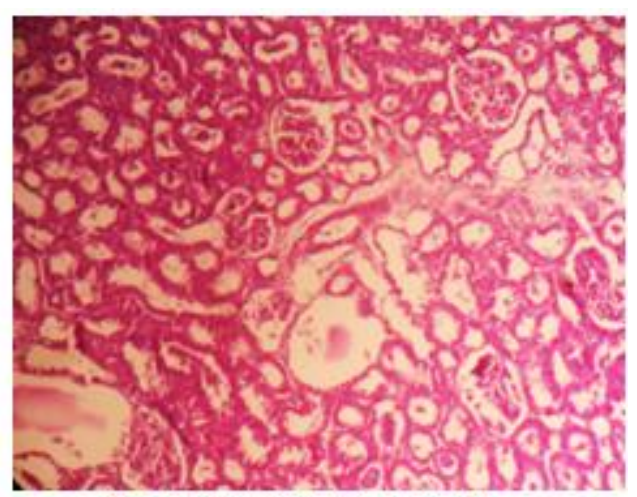

Figure (b) Diabetic Control

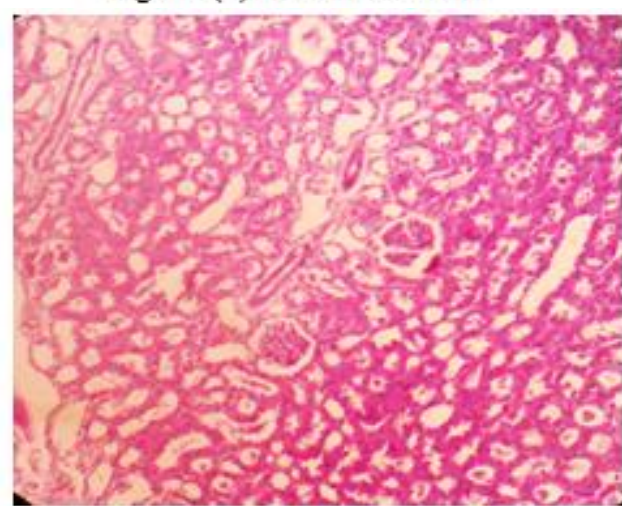

Figure (d): Glibenclamide treated

Figure: a - d: Histopathological changes of kidney in control and experimental rats

\section{Conclusion}

Based on the findings, it can be concluded that kombucha acts effectively against diabetes. These results support its implication of controlling blood glucose levels and may be slowing or even reverse some of the pathological conditions of diabetic nephropathy.

\section{References}

[1] Selby, J. V., Fitz Simmons, S. C., Newman, J. M., Kats, P. P., Sepe, S., Showstack, J. (1990), —The natural history and epidemiology of diabetic nephropathy: Implications for prevention and control". The Journal of the American Medical Association, 263, 1954-1960.

[2] Ritz, E., Zeng, X. X., Rychlik, I. (2011), Elinical manifestation and natural history of diabetic nephropathy". Contributions to Nephrology, 170, 1927.

\section{Volume 5 Issue 3, March 2016}


[3] Hovind, P., Tarnow, L., Rossing, K.et al., (2003), Đecreasing incidence of severe diabetic microangiopathy in type 1 diabetes". Diabetes Care, 26(4), 1258-1264.

[4] Ha, H., and Lee, H. B. (2000), Reactive oxygen species as glucose signaling molecules in mesangial cells cultured under high glucose". Kidney International, 58(77), 19-25.

[5] Jayabalan, R., Malbasa, R. V., Loncar, E. S., Vitas, J. S., and Sathishkumar, M. (2014), -A Review on Kombucha Tea-Microbiology, Composition, Fermentation, Beneficial Effects, Toxicity, and Tea Fungus". Comprehensive Reviews in Food Science and Food Safety, 13, 538-550.

[6] Chu, S. C., and Chen, C. (2006), Effects of origins and fermentation time on the antioxidant activities of kombucha”. Food Chemistry, 98, 502-507.

[7] Parthasarathy, R., Ilavarasan, R., Karrunakaran, C. M. (2009), Antidiabetic activity of Thespesia Populnea bark and leaf extract against streptozotocin induced diabetic rats". International Journal of PharmTech Research, 1(4), 1069-72.

[8] Gornall, A. G., Bardawill, C.J., David, M. M. (1949), Đetermination of proteins by means of the biuret reaction". Journal of Biological Chemistry, 177, 751766

[9] Doumas, B. T., Watson, W. A., Biggs, H. G. (1971), Albumin standards and the measurement of serum albumin with bromocresol green". Clinica Chemica Acta, 31, 87-96

[10] Eid, S., Maalouf, R., Jaffa, A. A., Nassif, J., Hamdy, A., Rashid, A., Ziyadeh, F. N., Eid, A. A. (2013). z0HETE and EETs in diabetic nephropathy: a novel mechanistic pathway". PLOS One, 8(8), 70029.

[11] Rasch, R., and Mogensen, C. E. (1980), Urinary excretion of albumin and total protein in normal and streptozotocin diabetic rats". Acta Endocrinology, 95,376-381

[12] Musabayane, C. T., Mahlalela, N., Shode, F. O., Ojewole, J. A. (2005), Effects of Syzygium cordatum (Hochst.) [Myrtaceae] leaf extract on plasma glucose and hepatic glycogen in streptozotocin-induced diabetic rats". Journal of Ethnopharmacology, 97, 485- 490.

[13] Jefferson, L. S., Liao, W. S. T., Peavy, D. E., Miller, J. B., Appel, M. C., Jaylor, J. M. (1983), Điabetes induced interactions in liver protein synthesis. Changes in the relative abundance of mRNAs for albumin and other plasma proteins". Journal of Biological Chemistry, 258, 1369-1375.

[14] Burcelain, R. M., Eddouks, J., Maury, J., Kande, R., Assam, and Girard, J. (1995), Excessive glucose production rather than insulin resistance accounts for hypoglycaemia in recent-onset diabetic rats". Diabetologia, 38, 283-290.

[15] Mauer, S. M., Steffes, M. W., Brown, D. M. (1981), The kidney in diabetes". American Journal of Medicine, 70, 63-6.

[16] Almdal, J.P., Vilstrup, H. (1988), Strict insulin therapy normalizes organ nitrogen contents and the capacity of urea nitrogen synthesis in experimental diabetes in rats". Diabetologia, 31,114-8. 